\title{
The Sustainability Babel Fish
}

\author{
Ory Zik $\cdot$ Nalin Kulatilaka
}

Received: 17 August 2011/ Accepted: 29 May 2012

(C) The Author(s) 2012. This article is published with open access at Springerlink.com

\begin{abstract}
This paper proposes a quantitative measure of sustainability. Using primary energy as a metric, it enables decisions to be made across different activities such as electricity, fuel and water use. By relying on bill data, we eliminate the need for new measurements and readily connect to economics through market prices. We choose the primary energy content of a gallon of gasoline as the basic unit, which turns out to be the right size to appeal to common intuition. We highlight that there are no 'one size fits all' rules governing sustainability decisions. Rather, the appropriate choices depend on location, time, and personal attributes.
\end{abstract}

Keywords Energy efficiency · Quantitative sustainability · Climate change $\cdot$ Environmental behavior

Babel Fish: “Arthur Dent commented only 'Eurgh!' when first inserting the fish into his ear. It enabled

Handled by Fabio Orecchini, University of Rome "La Sapeinza", Italy.

O. Zik is a major shareholder in Energy Points and the EnergyPoints ${ }^{\mathrm{TM}}$ system is patent pending.

\section{O. Zik}

Zik Energy Points Inc., 614 Massachusetts Avenue, Cambridge, MA 02141, USA

e-mail: oryzik@energypoints.com

N. Kulatilaka $(\square)$

Wing Tat Lee Family Professor of Management, School of Management, Boston University, 595 Commonwealth Avenue, Boston, MA 02215, USA

e-mail: nalink@bu.edu him to understand Vogon Poetry—not necessarily a good thing". The Hitchhiker's Guide to the Galaxy, Douglas Adams.

\section{Introduction}

We rely on common systems and quantitative signals (e.g., price, temperature, food calories) to support everyday decisions. Timely decisions are made, not with precise measures, but with familiarity and suitable approximations. Such quantitative intuition about sustainability is, for the most part, absent. There is a glaring void in our ability to quantify and capture the impact of our actions on sustainability. Although separate data streams are measured with increasing granularity, we do not have a way to grasp quantitatively the impact across different domains-e.g., driving a car, heating a house, running an air conditioner or watering a lawn. Whether it is in formulating national policy, corporate strategy, or individual actions, we are muddling through a fog.

This gap is not adequately filled with $\mathrm{CO}_{2}$ accounting. While $\mathrm{CO}_{2}$ addresses climate change, it is difficult to measure, does not provide quantitative intuition, and has also become a divisive issue that hinders the coalescence of political support. These concerns have been noted by many, including Mackay (2009), who used basic physics principles to establish a per capita estimate of energy use to quantify sustainability.

Having a quantifiable measure is only step one. In order to influence decisions, the measure must be readily observed and interpreted. Van Houwelingen and Van Raaiji 1989) reported that visual monitoring of energy expenses improves energy conservation by more than $12 \%$, but it persists only as long as the visual reminder is intact. In a recent study, 
Attari (2010) demonstrated that there is a gap between reality and perception even when limited to decisions involving a single type of energy like electricity used to operate lights and appliances. It adds to a growing literature demonstrating the value of feedback, preferably visual, in a broader decision-making context to motivate behavior leading to energy efficiency (Allcott 2010; Ariely 2008).

The unmet need is for a visual, quantitative, and actionable system that can support decisions. In order to alleviate the need for a constant reminder, such a measure must become intuitive (Kahneman 2011). Furthermore, an effective system must be linked tightly to economics and, with its widespread adoption, be able to leverage social networks that impact behavioral norms.

In this paper we make a bold attempt to fill this void. We propose a points system based on energy that enables informed decisions across different domains of energy use and captures the total impact on sustainability, at least to the first order of accuracy. Although we focus our attention on energy and water, our methodology can be extended to include all scarce resources, including those embodied in products, as well as reflects the impact of externalities resulting from effluents. Our work hinges on the conjecture that quantitative intuition, coupled with visual feedback and appropriate incentives can bridge the reality/perception gap and provide the sustainability analogue of a points system used in a successful diet (Freedman 2011). Furthermore, the economic appeal of our proposal is enhanced through its direct link to oil prices. The constant visibility of oil prices increases awareness and serves as a natural choice to induce sustainable behavior (Ariely 2008), being an ideal platform for building 'system one' type intuition.

Given its simplicity, transparency and visibility, the energy points system can become a universal translator-a Babel Fish - that will drive behavioral change.

\section{The basic building block: an energy point}

Our basic unit of accounting is the primary energy ${ }^{1}$ (Annual Energy Review 2010) content of a gallon of gasoline, which we define as an energy point (EP). The energy consumed while driving (gasoline), heating a building (natural gas), or operating a data center (electricity) are readily translated to EP and placed on a comparable scale. EP can be extended to include embodied energy in products, material use, and account for externalities due to effluents.

\footnotetext{
1 We choose primary energy to conduct the correct comparison with electricity and other energy forms. Notice that we focus on relative measures in comparison to gasoline rather than absolute.
}

Why choose a gallon of gasoline as our unit of measure? For most people, gasoline combines a familiar and 'physical' experience of energy with the visibility and 'pain' of cost at the pump. It connects to vital economic, national security, and environmental concerns. The intuitive link to economics is simple and direct_-via the price of oil. The high energy density of gasoline of about $35 \mathrm{kWh} /$ gallon (Davis et al. 2010) makes it the right scale to measure the meaningful impact of most day-to-day activities. Since we rate primary energy and our unit of measure is a gallon of gasoline, we need to take into account the losses that are incurred in the process of refining and transporting the primary energy to the refined product used by the end user. In the case of gasoline, average losses are estimated to be $17 \%$ (DoE 2000). Therefore, in comparing to other primary energy sources, a gallon (1 EP) is rated as $42.2 \mathrm{kWh}$ $(=35 / 0.83)$ primary energy.

\section{Comparing across different energy domains}

Consider a household as the decision-making unit and a month as the relevant accounting period. ${ }^{2}$ For pedagogical simplicity, we only consider the operational energy consumption. Energy use in capital, infrastructure and other embodied energy, will be dealt with later. First, let us consider the gasoline used in automobile travel and electricity used by a household.

In order to build intuition, we use energy per gallon (EPG) measured in $\mathrm{kWh} / \mathrm{EP}$ drawing the analogy to the familiar energy efficiency function for automobiles-miles per gallon (MPG). EPG will be determined by the local and temporal ${ }^{3}$ electricity mix. The energy used for driving and electricity use can be stated in terms of the common unit, EP, as ${ }^{4}$ :

$E_{\mathrm{Car}}(\mathrm{EP})+E_{\mathrm{Elec}}(\mathrm{EP})=\frac{\text { miles }}{\mathrm{MPG}}+\frac{\mathrm{kWh}}{\mathrm{EPG}}$

Let us assume a local power generation efficiency of $50 \%$ (meaning that $50 \%$ of the primary energy is converted to electricity). In other words, the EPG for electricity in this region is $21.1 \mathrm{kWh} / \mathrm{EP}$. A family that drives 1,000 miles a month in a $20 \mathrm{MPG}$ car, and consumes $1,000 \mathrm{kWh}$ of electricity, is expending $50 \mathrm{EP}$ each for driving and electricity use. Since most people do not know their consumption in $\mathrm{kWh}$ but know only the

\footnotetext{
2 The notion will carry through apply similarly for any billed unit (e.g., business unit in a company) and any accounting period.

3 Due to on and off peak consumption.

${ }^{4}$ Fixed costs may be considered to reflect the EP associated with the various infrastructure (distribution network). In later work we show how the deployed capital and externalities can be incorporated into EP.
} 
dollar value of the electricity bill, we can state the energy use in terms of the expenditure reported in the monthly bill:

$E_{\text {Elec }}(\mathrm{EP})=\frac{B_{\text {Elec }}(\$)}{\mathrm{EPG} \cdot C_{\mathrm{Elec}}}$,

where $B_{\text {Elec }}$ is the monthly dollar electricity bill, and $C_{\text {Elec }}$ is the unit cost of electricity in US $\$ / \mathrm{kWh}$.

We now extend and generalize to include all energy services, using typical consumption (or bill) information, and making the necessary adjustments through the price to derive the total energy consumed ${ }^{5}$ :

$E(\mathrm{EP})=\sum_{s}\left[\frac{B_{s}(r)}{\mathrm{EPG}_{s}(r / \mathrm{EP})}\right]$

where $B_{\mathrm{S}}$ is the monthly consumption of resource $s$ (electricity, water, gas etc) measured in the resource unit $r$ (e.g., $\mathrm{kWh}$, kgal, mBTU etc.). The EPG depends on the efficiency of the conversion technology. The beauty of this equation stems from several features. First, is its simplicity. Second, the fact that the independent variables are directly captured in existing measurement systems (bills), and finally EPG is typically a local (possibly personal) number. As with the MPG of a car, it is easy to build quantitative intuition around the EPG of any energy-using asset.

Let us now turn to the computation of EPG for electricity generated from different primary energy sources. As a first approximation, assume all primary energy derived from fossil sources (coal, oil, natural gas) to be equivalent with respect to the losses associated with mining and extracting. The next question is how to weigh electricity according to the amount of primary energy required to generate it, taking into account the local electricity mix. Each generation type will have an associated EPG. The EPG values are determined by the amount of $\mathrm{kWh}$ electricity output per unit of $42.2 \mathrm{kWh}$ primary energy input. In other words, EPG is calculated relative to a gallon of gasoline, not in absolute terms. For example, the high conversion efficiency of Combined Cycle Natural Gas plants results in electricity EPG value of $27 \mathrm{kWh} / \mathrm{EP}$. Lower efficiencies of coal power plants reduce their electricity $\mathrm{EPG}$ to $8 \mathrm{kWh} / \mathrm{EP}$. In contrast, the only primary energy use in generation from sources like wind and solar is in the embodied energy of the equipment and land use, and results in EPG values of greater than $42.2 \mathrm{kWh} / \mathrm{EP}$ for renewable electricity. This ensures that the EP system gives the correct preference to renewable energy.

The EPG for electricity in any particular region at a particular time depends on the deployed generating mix. The portfolio EPG can be obtained by calculating the

\footnotetext{
5 In later work, we show how the deployed capital and externalities can be incorporated into EP.
}

electricity mix as the follows, where $W_{\mathrm{i}}$ is the fraction of $\mathrm{kWh}$ produced by resource type $i: \mathrm{EPG}^{-1}=\sum_{i} W_{i}\left(\mathrm{EPG}_{i}\right)^{-1}$

The resource portfolios are typically geographically dependent and our general preference to trade accuracy for simplicity while preserving the impact on the decision making. Local approximations tend to convey far more meaningful information to decision makers than overly precise averages. Most sustainability decisions are taken on a relative or comparable basis. In order to derive an ordinal ranking of disparate activities, we still need a quantitative scale. The scope of the current work is to establish the framework for intuition by providing the correct unit and scale. Therefore, like in a food diet, the absolute numerical values should be treated with caution. We have, however, made every effort to capture the gist of the problem with sufficient accuracy to ensure that correct decisions are reached.

\section{Extending energy intuition to water}

To demonstrate how EP can be extended to other sustainability metrics, it is natural to start with water. With sufficient energy, water can be conveyed from where it is abundant to places of scarcity or where it can be desalinated. On the other hand, increased pumping needs tend to align peak water usage with peak electricity usage. The 'water-energy nexus' (Energy Demands on Water Resources 2006) is further complicated by the large amounts of water required for the harnessing of many primary energy sources (e.g., shale gas) and power generation. Water scarcity and pollution can dramatically impact the EP value (and associated true cost) of water (Gleick 2010), while legacy practices have created water-pricing policies that do not reflect availability or value added, and thus lead to perverse incentives in water use in agriculture and industry. The cost (and energy requirements) of water does not end at the point of consumption, but extends to disposal and treatment of sewage, thus increasing the per gallon cost of water consumption (Gellings 2009).

The energy intensity of the water system, $I_{\mathrm{W}}$, can be divided into two components. The first is geographically dependent and the other is fixed. The first component is sensitive to local and temporal variations such as flow, precipitation, evaporation and withdrawal. The intensity depends on water acquisition technology from surface reservoirs or underground aquifers, brackish water or seawater desalination. This component involves conveyance, which depends on distance and elevation difference between source and use. The second component is fixed. It includes filtration and storage as well as wastewater collection and treatment. 
In order to develop quantitative intuition, we use the following approximations, ordered by water energy intensity, $I_{\mathrm{W}}$ : surface water withdrawal $(0.4 \mathrm{kWh} / \mathrm{kgal})$, waste water reuse $(1.6 \mathrm{kWh} / \mathrm{kgal})$, ground water pumping ( $2 \mathrm{kWh} / \mathrm{kgal})$, imported water $(3.5 \mathrm{kWh} / \mathrm{kgal})$, brackish water desalination $(5 \mathrm{kWh} / \mathrm{kgal})$, deep groundwater withdrawal $(6 \mathrm{kWh} / \mathrm{kgal})$ and seawater desalination $(13 \mathrm{kWh} /$ $\mathrm{kgal})$. We add a value of $4 \mathrm{kWh} / \mathrm{kgal}$ for the fixed component (Gellings 2009) and take into account the overall water losses, which range typically from 0.1 to $25 \%$.

To establish a benchmark, let us calculate water efficiency $\mathrm{EPG}_{\mathrm{W}}$ in $\mathrm{kgal} / \mathrm{EP}$ at two extreme cases. Low efficiency case: water from desalination using electricity generated from coal and incurring $25 \%$ conveyance losses resulting in $\mathrm{EPG}_{\mathrm{W}}=0.35 \mathrm{kgal} / \mathrm{EP}$. High efficiency case: using surface water with only $10 \%$ losses using electricity from combined cycle natural gas resulting in $\mathrm{EPG}_{\mathrm{W}}=$ $5.5 \mathrm{kgal} / \mathrm{EP}$. We see that technology use, dictated by local conditions, imply an order of magnitude variation in $\mathrm{EPG}_{\mathrm{W}}$.

\section{Consolidated monthly energy budget}

We now consolidate the sustainability of the household's activities using EP in a manner similar to how multinational businesses consolidate global P\&Ls across multiple currency regimes. For example, a household with electricity use, car travel, and water use can convert these disparate activities to energy points in the following way:

$\mathrm{EP}=\frac{\mathrm{kWh}}{\mathrm{EPG}}+\frac{\text { miles }}{\mathrm{MPG}}+\frac{\mathrm{kgal}}{\mathrm{EPG}_{\mathrm{W}}}$

Let us demonstrate our approach where disaggregated energy budgets are presented for two hypothetical families in reference to the US average. For pedagogical simplicity we limit our attention to four categories of consumption: electricity, heating, ${ }^{6}$ car miles, and water. Family $A$ resides in a cold climate in an urban setting. They use natural gas for heating and purchase electricity generated from coal. Family $B$ lives in a suburban house in a warm climate where air conditioning needs are high, water is scarce, and natural gas is used only for cooking. They participate in a utility program that allows most of the electricity to be purchased from solar energy, leading to a high effective $\mathrm{EPG}=40 \mathrm{kWh} / \mathrm{EP}$. In order to focus on the key features salient to the present discussion, suppose that the families are comparable in other demographic aspects.

It is worthy of note that, first, all consumption information (numerators) that is needed to compute EP is

\footnotetext{
${ }^{6}$ Heating is assumed in natural gas, where $1 \mathrm{EP}=1.44$ therms.
}

gathered from readily observable sources, such as monthly utility bills. Second, local and personal effects about pricing policies, the value chains of the energy sources (e.g., buying green electricity) are captured in the translation factors (denominators). Finally, the extreme simplicity and round numbers build quantitative intuition and ease of use.

Figure 1 illustrates the results in a graphical way, assuming representative values. Several observations are worth noting:

1. Allows cross-domain comparison and consolidation Energy use of widely different activities can be presented on a common scale, thus allowing for easy comparisons and meaningful tradeoff decisions. For instance, electricity ( $\mathrm{kWh}$ ), heating (therms), car miles driven, and water use (gallons of water) are placed on the same scale.

2. One size does not fit all locations Precise global or national averages do not lead to correct local priorities. Local conditions (climate, fuel mix in electricity generation, resource availability) have a strong impact, and as a result local approximations turn out to be better than global averages. For instance, while the cold temperate climates place a heavy weight on heating, scarcity places a high weight on water in hot, dry climates.

3. Personal context matters Lifestyle factors determine the relative weights placed on the different categories and lead to materially different choices. For instance, buying a more fuel efficient hybrid vehicle will have a much smaller impact on the EP footprint of Family A's urban lifestyle (drive 150 miles per month) than Family B's suburban lifestyle (drive 1,500 miles per month).

This simple analysis highlights how the EP system can support a wide range of investment and behavior decisions that would otherwise be made in an uninformed fashion.

It is worthwhile to compare the values in Fig. 1 to other sustainability metrics such as greenhouse gas (GHG) emissions. A gallon of gasoline and a therm of natural gas can be converted readily to $\mathrm{CO}_{2}$ emissions using $11.2 \mathrm{kgCO}_{2}$ /gallon and $5.3 \mathrm{kgCO}_{2} /$ therm, while the conversion of electricity and water will depend on the local electricity mix.

Armed with 'personal translator'-Sustainability Babel Fish-and monthly bills, you are ready to benchmark your sustainability decisions across different domains. From capital decisions such as: what is best? LED lighting, drip irrigation, installing solar power, an electric car or attic insulation, to operational decisions such as carpooling with a given car versus turning the lights off or drip irrigation. Figure 1 provides not only a framework but also a practical decision rule to make such choices. When coupled with 
Fig. 1 Consolidated monthly energy point (EP) budget of four cases: family A in the Northeast spring (minimal heating expense), US average, family A in the NE winter month ( $\max$ heating) and family B in the Southwest summer. Notice the high relative value of water EP

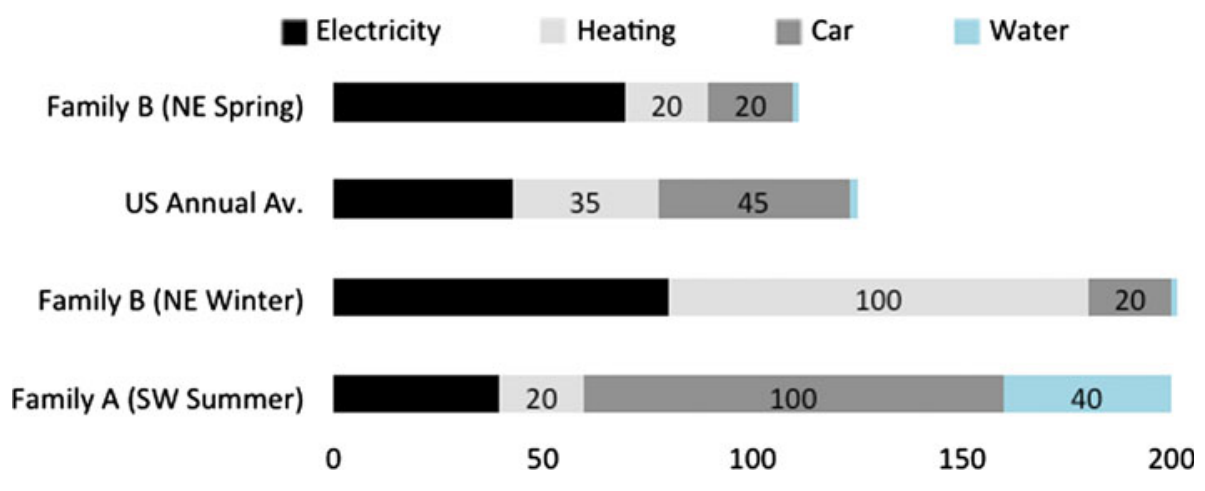

Fig. 2 An energy points bar-a quantitative personal sustainability scale

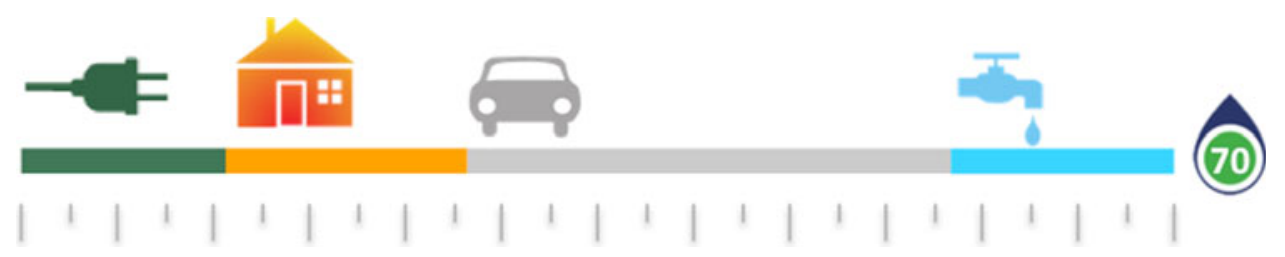

financial budgets associated with consumption categories, it facilitates decisions regarding dollars spent per EP and EP saved per dollar invested.

\section{Conclusions and policy recommendations}

The current state of our energy supply paints a very gloomy picture: burning oil adds to geopolitical instability and $\mathrm{CO}_{2}$ emissions that have dire effects on the climate; shifting to coal will exacerbate the environmental harm; renewable energy is no panacea-land and water use as well as intermittent supply impose severe constraints; nuclear power is still plagued with safety, waste disposal, and proliferation challenges while water exemplifies a mindset in which finite resources are still treated as infinitely available. How then do we achieve the twin goals of economic growth and sustainability?

Supply-side solutions alone will not suffice. We must find ways to affect demand as well. We believe that the first step is an intuitive yet comprehensive accounting system that can couple the impact of changes to the portfolio of energy sources with changes to consumption behavior. We have proposed an energy-based points system that can count sustainability parameters in an intuitive manner. Through the use of gasoline as a unit and relying on widely reported data sources, it links to strong motivating factors such as fuel cost and security.

The next step is action. How do we enhance the motivation to go on a sustainability 'diet'? Analogous to a food diet, we need a social norm and feedback mechanism, such as a scale or a 'mirror on our refrigerator'. The visibility and connection to bills of the EP approach offers a promising solution as it can be coupled with social networks such as the energy point bar (Fig 2). Furthermore, gaps in both quantitative intuition and multidimensional feedback are bridged with links to economics and environmental impact.

The natural extension is incorporating embodied energy and the rest of our consumption basket (e.g., food, capital goods), accounting for externalities (e.g., GHG emissions, land use and waste disposal), and the allocation of shared infrastructure resources (e.g., roads and public services). Although doing so introduces new levels of complexity, the basic logic still holds true. For instance, our preliminary calculations show that energy points for food and air travel are of comparable magnitude to electricity and driving, thus reinforcing the $E P$ concept as a practical decision support tool.

Although we chose to illustrate the concepts in the context of a family energy budget, our approach reaches beyond individual decision makers. It can provide a common framework for governments and corporations to synthesize the multitude of current sustainability indicators in a single measure. For example, corporate sustainability reports, which now use different metrics to report each data stream (kWh, Btu, miles, water gallons etc.), can be consolidated with EP as a single common measure.

There are unambiguous and far-reaching social benefits from a system like EP to measure sustainability. By providing an intuitive measure, it not only induces sustainable behavior by individuals but also serves as a credible mechanism for institutions or entire enterprises to signal their overall sustainability. Consequently, it will reduce the incentives for companies to engage in misguided initiatives that have spurious social benefits. By exposing deceptive "green-washing" activities, consumers will be able to choose and reward truly environmentally beneficial 
products. Furthermore, from a public policy perspective, EP can establish and enforce compliance standards across a broad set of activities.

Acknowledgments We wish to thank Fred Abernathy, Jennifer Call, Robert Kaufmann, David Lowe, Megan McGarvie, Udi Meirav, Ron Milo, Zeev Pearl, Roy Stein and David Waxman for fruitful discussions.

Open Access This article is distributed under the terms of the Creative Commons Attribution License which permits any use, distribution, and reproduction in any medium, provided the original author(s) and the source are credited.

\section{References}

Allcott H (2010) Behavior and energy policy. Science 327(5970): 1204-1205. doi: 10.1126/science. 1180775

Annual Energy Review (2010) October 2011. U.S. Energy Information Administration. Office of Energy Statistics. U.S. Department of Energy

Ariely D (2008) For the several minutes that I stand at the pump, all I do is stare at the growing total on the meter-there is nothing else to do. And I have time to remember how much it cost a year ago, two years ago and even six years ago. at Eyes Off the Price. NYT, July 19

Attari SZ (2010) Public perceptions of energy consumption and savings. Proc Natl Acad Sci USA 107(37):16054-16059

Davis SC, Diegel SW, Boundy RG (2010) Transportation energy data book. Oak Ridge National Laboratory, Springfield

DoE (2000) Corporate average fuel economy (CAFE). 10 CFR Part 474. http://www.gpo.gov/fdsys/pkg/FR-2000-06-12/pdf/ 00-14446.pdf

Energy Demands on Water Resources (2006) In: Report to Congress on the Interdependency of energy and water: US DoE

Freedman DH (2011) How to fix the obesity crisis. Sci Am 304(2):40-47

Gellings CW (2009) Program on technology innovation: electric efficiency through water supply technologies. EPRI, Palo Alto

Gleick PH (2010) Roadmap for sustainable water resources in southwestern North America. Proc Natl Acad Sci USA 107(50): 21300-21305

Kahneman D (2011) Thinking fast and slow. Farrar, Straus and Giroux, New York

Mackay DJC (2009) Sustainable energy without the hot air. UIT Cambridge, Cambridge

Van Houwelingen JH, Van Raaij WF (1989) The effect of goalsetting and daily electronic feedback on in-home energy use. J Consum Res 16(1):98-105 